\title{
Díptico viajero: Josep Pin i Soler en Bucarest y en Constantinopla
}

\author{
JUAN M. RIBERA LLOPIS (UCM) \\ jumriber@filol.ucm.es \\ Recibido: marzo del 2011. Aceptado: mayo del 2011.
}

\begin{abstract}
Resumen: Aproximación a la literatura de viajes de Josep Pin i Soler, atendiendo a dos destinos que lo aproximaron a las puertas de Oriente, Bucarest y Constantinopla. En estas ciudades el escritor viajero contrastará modelos sociales de convivencia ante los que evidenciará sus ideales cosmopolitas y liberales. ${ }^{1}$
\end{abstract}

Palabras clave: Literatura catalana contemporánea. Literatura de viajes y destinos urbanos. Josep Pin i Soler. Bucarest y Constantinopla. Categorías urbanas. Cosmopolitismo y liberalismo.

\begin{abstract}
An approach to Josep Pin i Soler's travel literature, according to two destinations that took him to the gates of the East, Bucharest and Constantinople. In these cities, the traveller writer will compare the social coexistence models, showing his cosmopolitan and liberal ideals.
\end{abstract}

Keywords: Contemporary Catalan Literature. Travel Literature and urban destinations. Josep Pin i Soler. Bucharest and Constantinople. Urban categories. Cosmopolitanism and Liberalism.

${ }^{1}$ De la aproximación a la literatura de viajes de J. Pin i Soler y de las impresiones del autor sobre Bucarest, contenido aquí tratado y revisado, una primera versión está publicada en el volumen Bucarest: luces y sombras, D. Muñoz Carrobles, J. J. Ortega Román (eds.), Sevilla, Grupo Nacional Editores, 2009, pp. 189-203; por otra parte, una primera versión editorialmente inédita de las páginas dedicadas a la estancia del autor en Constantinopla, fue presentada en International Colloquium Xenographies, BCLA \& SELGYC (University of Wolverhampton, UK, 2009). Tota esta secuencia de trabajo se ha realizado dentro del Proyecto de Investigación I+D, HUM2007-60329, Viajar por la ciudad: modelos urbanos en los libros de viaje y su proyección estético-literaria, Ministerio de Educación y Ciencia (01/10/2007-30/09/2010), investigadora principal Dra. E. Popeanga Chelaru (UCM). 


\section{ESCRITURA, VIAJE I VIAJERO SEGÚN JOSEP PIN I SOLER}

Destacado en la historiografía literaria catalana por una obra narrativa mentada desde 1869 y dada a conocer, con gran éxito de crítica y público, mediante su trilogía fundamental entre los años 1887 y 1890, Josep Pin i Soler (18421927) escribe, tanto como novelista como dramaturgo, desde unas claves realistas que, si bien intentaban superar los límites de un patriarcalismo ingenuo y sentimental con raíces ruralistas, tropezaron en sus manos con problemas de orden estructural así como con una no disimulada tendencia a la digresión. Este indicio sobre su solución lingüístico-literaria quizás se pudiera entender o tal vez se sustentara tanto en su rechazo expresado en repetidas ocasiones a cualquier filiación literaria, como en su labor de publicista que le llevaron a concebir una escritura mixta, poco encasillable no sólo en los márgenes de una escuela literaria concreta sino también en los de un perfil genealógico definido.

Lo cierto es que el joven Pin i Soler, de tempranas veleidades literarias, por su aproximación al espíritu liberal de los sesentayochistas decimonónicos y merced a su directa participación en la revuelta estudiantil madrileña de 1865, tuvo que exiliarse en dirección hacia Ginebra, París y Bruselas, en un itinerario que acabaría por recalar en Marsella. Situación que se prolongaría durante veintitrés años, durante ese tiempo el también escritor sobrevivió mediante las más variadas profesiones y actuaciones; entre ellas y por lo que se refiere al ejercicio de la escritura, como autor de crónicas musicales en la prensa francesa, práctica que le llevaría a ser también articulista en publicaciones catalanas de expresión catalana o castellana, por ejemplo en La Renaixensa, El Poble Català, Joventut, La Vanguardia, Diario Español, La Prensa, Foment o Catalana, así como colaborador en la madrileña La Esfera (v. selección en Pin i Soler, 2004a). De esa experiencia continental que le permitiría viajar por buena parte de Europa, surgiría así mismo la composición de la crónica viajera, género híbrido donde el autor podía combinar la impresión de una experiencia o de una imagen con el relato de un encuentro o de una anécdota y también, ai las!, con la digresión inevitable de quien está resuelto a informar sobre curiosidades de las gentes y de los paisajes visitados y a emitir juicios al respecto o sobre el propio hecho del viaje y la misma naturaleza del viajero. Reunida parte de ese material - previamente aparecido en Joventut y El Poble Català - en tres volúmenes bajo el título Vària (1903-1906), serie a la cual el escritor tenía pensado añadir al menos dos textos más sobre Bélgica y Portugal (Solà 1966: 9-10) y a la que cabría adjuntar algún texto periodístico que menciona algún que otro puntual destino viajero (por ej. Ostende en Pin i Soler, 2004a: 29-31), tal vez se halla aquí una muestra germinal del tintero en el que se mezclaban las maneras de escribir que no tenían por qué emerger en superficies textuales definidamente uniformes; seguramente, además y tal y como se ha destacado en ocasiones, se evidencia el lecho profundo de un autor que, por lecturas y periplo, disponía de una cultura y una visión del mundo más amplía que la mayoría de sus compatriotas.

La literatura de viajes de Josep Pin i Soler ha sido estudiada como un capítulo intermedio en su producción, entre la propiamente narrativa y la calificada como humanista - la producción del traductor y prologuista así como la del educador- $-\mathrm{y}$, a la vez, como pionera respecto de ese modo de hacer en las letras ca- 
talanas junto a títulos de Gabriel Alomar o también de Maria Antònia Salvà, tras los textos canónicos de Víctor Balaguer y Jacint Verdaguer y ante el crescendo de volúmenes hacia los años veinte del novecientos (Pujals 1994: 291-292). De su propia escritura y como viajero, el autor sale autorretratado, a caballo de aquellos dos estadios y todavía, como «...en gran part, un viatger romàntic», dado su interés por lo pintoresco y su sentimiento por la desaparición de los signos distintivos del pueblo visitado (Solà 1966: 10); como un viajero «... amb un bagatge de romanticisme» (Pujals 1994: 292). Pero tanto M. Solà como J. M. Pujals, los dos estudiosos ya mencionados que se han acercado a la literatura de viajes de Josep Pin i Soler, destacan respectivamente que el escritor no es ajeno a un interés viajero más moderno, atento a la realidad social, política y económica, al margen de que lo evidencie desde un estatus privilegiado desde el cual tampoco persigue una interpretación en profundidad (Solà 1966: 10-11); también que proyecta sobre la realidad visitada una cultura libresca a la vez que propicia una tolerancia no exenta de ironía, resultado de una justa combinatoria entre erudición y empirismo viajero (Solà 1966: 10; Pujals 1994: 291). Cierto, se nos advierte también en esas mismas páginas, que al escritor le cabe abandonarse, desde esos presupuestos, en la mencionada tendencia a la digresión - en ocasiones pedante aunque sin llegar a lo desagradable, de acuerdo con M. Solà- y que, por esa vía, se alcanza una interpretación de lo humano que, de acuerdo con M. Solà, tiende al abstractivo esencialismo universal o, según J. M. Pujals, a un patrón reduccionista marcado por una visión costumbrista que equipara hábitos de aquí y de allá. Pensemos que la mencionada matriz romántica tanto propiciaba lo uno como lo otro.

Por otra parte, ambos críticos mencionan ciertas limitaciones en la escritura de Josep Pin i Soler acerca de sus viajes, alguna ya advertida en su tiempo por Josep Yxart a propósito de su obra narrativa. De ello resulta una flagrante desigualdad en los resultados que se evidencia, por ejemplo, en el desorden de los contenidos o en las descripciones interesantes que ciertamente aparecen junto a otras incoloras o inexistentes, sugiriéndose una equívoca complicidad con el lector cuando lo cierto es que deja las cosas presentadas a medias o pasando sin más por ellas; también en el uso de rápidas pinceladas que, más que juego impresionista, desconciertan a un receptor que sólo en contadas ocasiones halla un acertado esbozo; indicios negativos de una prosodia junto a los cuales también se reconoce el uso coherente del flash, de la voz en off o de un criterio selectivo ante la posible acumulación informativa en según qué casos y a merced de una planificación esquemática de lo que se desea transmitir (Solà 1966: 11; Pujals 1994: 292-297). Todo ello va más allá de la mencionada mixtura o indefinición de modos de escritura cuando la verdad es que Josep Pin i Soler cuenta con una variada cultura literaria; la que le convierte en un erudito que, de acuerdo con M. Solà y J. M. Pujals, sabe evitar los riesgos de la pedantería y que, por tanto, no va dando palos de ciego intelectualmente hablando; y que, en el caso de la literatura de viajes, nos ha quedado preciosamente documentada.

Un volumen de edición póstuma del año 1947, Comentaris sobre llibres $i$ autors (Pin i Soler 2004b), pone a nuestra disposición el catálogo con muchas entradas comentadas de la biblioteca personal del autor. Además de lo que podemos apreciar como descripciones geográficas de los más variados países y rin- 
cones, dicho catálogo ordena la presencia en aquel fondo bibliográfico de muchos y muy específicos libros de viajes: sin ánimo de ser exhaustivos y puestos a no citar rarezas, desde títulos de referencia antiguos o modernos como los de Marco Polo y Alí Bey-el Abbasi o Domingo Badía y Leblich a firmas castellanas como Alarcón o Ganivet, catalanas como Alomar, Balaguer, Gaziel, Rusiñol o Verdaguer, o de clásicos extranjeros como Amicis, Cook, Gautier, Irving, Loti o Staël, además de la del meta-viajero Jules Verne y de la denostada guía Baedecker. Lector, por tanto, de literatura de viajes, cuesta entender a un Pin i Soler que no atendiera a unas leyes del relato viajero, que se abandonara a los propios impulsos o que no revisara sus personales incursiones en ese género. Sólo cabe pensar en premura o ligereza a la hora de destinar sus textos a la prensa; quizás, también, en la mencionada comprensión flexible de los modos de escritura que, a la postre, le hizo cometer a Josep Pin i Soler más de un desliz.

Por encima de ese margen de equivocación, lo que sí es cierto es la valoración por parte suya del viaje como insustituible experiencia existencial y cultural. Como tal lo vemos destacado ya sea a la hora de introducirnos en la vida de Erasmo en la introducción a su traducido Elogi de la follia y oponiéndolo positivamente contra la vida claustral (Erasmus 1910: XV), ya sea en el momento de sintetizar los fundamentos educativos básicos, entre los que hay que contar con «... lo més important de la geografia y de la historia», tal y como resume en sus didácticas Regles morals y de bona criança Pin i Soler 1915: 91). En ese sentido, cuando en idéntica línea pedagógica conciba su Libro de la patria: coloquios sobre cosas y tierras de España (1923) - título que traza un recorrido geográfico e histórico español, con un ánimo reivindicativo de la propia idiosincrasia patria que ha llevado a hablar de su creciente españolismo pero que, en claves que podemos leer como iberistas, ya encontramos, por ejemplo, en el Viàtic de Vària III, texto fechado en 1905 (Pin i Soler 2002: por ej. 12)-, no sólo advierte en un texto que proviene del original catalán que encabezara su periplo más oriental tal y como constataremos mediante una cita posterior, que es «...inútil que vea tierras nuevas» quien «...no sepa el valor ético, artístico, histórico de lo que siempre ha visto en su tierra...» pues «Todo le parecerá igual, nada hallará que le interese...», sino que, añade:

Es también preciso, para viajar con fruto, dejarse llevar por la gente o la influencia de las cosas, entregarse, por ejemplo, al llegar a una ciudad desconocida, entregarse, relativamente, al criado o dependiente de la casa adonde penséis ir, dándole el talón de vuestro equipaje, sin discutir, siguiendo sus pasos, distribuyendo propinas entre cuantos hagan o parezca que quieren hacer algo en vuestro obsequio; no siguiendo los consejos del detestable Baedecker, a quien tanto preocupan las propinas y los mendigos. (...)

Ya en vuestra posada, lujosa o modesta, después de las abluciones de ritual, podéis echaros a la calle para ver cosas, advirtiéndoos que éstas serán más o menos elocuentes, según sea vuestra preparación. (Pin i Soler 1923: 318).

Anunciando directamente las indicaciones servidas por Josep Pla en pareja situación aunque en destino italiano (Pla 1969: 10-11), coincidencia que hace pensar que ambos remiten a un tópico en la coetánea literatura de viajes, ese um- 
bral del último párrafo, conclusión y a la vez tránsito hacia el entorno visitado, se muestra como invitación al conocimiento, expresión del «esperit obert» que M. Solà reconoce en Josep Pin i Soler (Solà 1966: 10). Conjuntamente, de toda la última cita y a favor de la mencionada amplitud intelectual se deduce una complementaria voluntad de autoconocimiento y de universalismo por parte del autor que, pensamos, se proyecta sobre las constantes de humanismo y de cosmopolitismo que M. de Montoliu le reconoce en la monografía que en su día le dedicara. El perfil de Josep Pin i Soler dibujado por este último critico compagina «... su humanismo, su humorismo y su cosmopolitismo» como combinatoria sobre la que el creador literariamente independiente superara el costumbrismo decimonónico; la vigencia del «educador» comprensivo pero que a la vez podía ser irónico y satírico con el exponente de un cosmopolitismo «...fruto de su personal experiencia y conocimiento de los hombres de los más variados climas y latitudes»; y el complementario «...humanismo cosmopolita...» que finalmente acabara por emerger a través de un «...cosmopolitismo intelectual bellamente armonizado con el amor a la tierra y con su españolismo tan recio como comprensivo...» (Montoliu 1947: 14-15, 16, 19, 12, 15, 8, 12). Texto el de M. de Montoliu que por fecha y finalidad debe cuadrar algunos extremos a los que, ciertamente, no fuera ajeno el propio Josep Pin i Soler en su creciente inclinación hacia la derecha más hispanamente conciliadora, cabe quedarnos de su esbozo con la figura del «aristócrata» que lo fue por «distinción» y con «naturalidad» (Montoliu 1947: 9), del personaje hecho a si mismo y con «...porte de gran señor» como lo recuerda su hijo Armando Pin de Latour y que, puesto a viajar y a escribir sobre sus viajes, pudiera recordarnos «...las mejores páginas de D'Amicis, Alarcón y Pierre Loti» (Montoliu 1947: 52, 57).

Sobre ese patrón podemos acercarnos a los textos de un escritor que informa desde unas prebendas en las que se reafirma, desde un estatus que, mencionado queda, no le hace involucrarse en según que causas, pero que no se desinteresa de los más variados ángulos del espectáculo que discurre ante sus retinas ni deja de aprovechar la experiencia viajera como ejercicio de personal aprendizaje. Para él, estas son las cláusulas que dotan de sentido a todo viaje:

Per viatjar una mica lluny de casa cal portar diners, mudades de roba, lletres per a persones del país on se va, gosar de bona salut i sobretot dur un Viàtic que no ocupa lloc i és més necessari que la roba i la moneda: saber d'on se ve, saber a on se va.

Qui no es conegui a si propi perdrà el temps volent estudiar als altres, qui no sapiga el valor ètic, artístic, històric de lo que sempre ha vist, és inútil que vulga veure coses noves. Tot li semblarà igual, res li semblarà digne d'interès, tornant-se'n a casa amb la impressió de bons dinars, de mals dinars, de fondes barates, d'hotels cars, de trens ràpids, de trens calmosos, de registres a les fronteres, de baüls capgirats... total res!, impressions de maleta sensible. (Pi i Soler 2002: 9).

Este texto, en catalán y de recurrente aprovechamiento por parte de su autor, continúa con las aseveraciones que antes, en castellano, le leíamos a Josep Pin i Soler acerca de los plausibles hábitos del viajero y en contra de cierta guía y de 
sus fieles seguidores, añadiendo en aquella ocasión las pautas recuperadas por Josep Pla. Al texto catalán previo se le adjuntaba la siguiente consideración:

Dèiem doncs que s'ha de saber lo que són les coses que es veuen, essent evident que per l'home ignorant les coses solament expresen lo que són en llur forma o llur matèria i que per l'home enterat tot parla i té vida. (Pin i Soler 2002: 10).

Por cada una de estas razones creemos que Josep Pin i Soler puede posicionarse contra el viajero snob, falsamente cosmopolita, aquel que, sencillamente, no sabe sacar verdadero provecho de sus privilegios o, simplemente, frivoliza la aventura. El escritor y viajero catalán se mostrará en contra de tal patrón a pesar de que tal espécimen lleve el nombre de Stanley, quien le confesara personalmente que sólo bebía champagne en sus viajes, siempre de la misma marca, nada de aguas de origen nativo; o aun cuando fuera «...un conegut nostre, gan funcionari del Congo belga» que no se desplazaba por la selva si no era acompañado de congeladores, camas desmontables, bañeras de aluminio, entarimados... (Pin i Soler 2002: 14-15). Y esto, pensamos, es lo que a Josep Pin i Soler no le ocurre y lo que no practica cuando sus pasos discurren por un Bucarest que, de entrada, es la capital más moderna en los límites del continente europeo; ciudad que, por ejemplo, le permitirá instalarse en un confortable hotel, pero la misma que, a la postre, no puede ocultar al viajero perspicaz su doble naturaleza, un contraluz ante el cual él no pasa de puntillas. Ni mucho menos ante Constantinopla-Estambul como destino igualmente hecho de extremos que, no obstante, parecen buscar una solución ideal. Un Bucarest total que Josep Pin i Soler y de acuerdo con una indicación suya posiblemente visitó en dos ocasiones, quizás en viajes distintos o entre su ida a y vuelta de Estambul, final de trayecto al parecer fundamental al que dedicara muchas páginas (Pin i Soler 2002: 79-131); siempre suponiendo que la ruta tomada hacia el Cuerno de Oro pasara por la ciudad dacia o a la inversa, tal y como nos prueban otras ordenaciones viajeras coetáneas, por ejemplo la contenida en el volumen correspondiente de Viajes por Europa. Turquía y los estados danubianos (1896) de Alfred Opisso. Lo cierto es que, tratando del edificio del Ateneo bucarestino, Josep Pin i Soler indica que si primero «...l'hem vist en construcció per lla vers l'any $80 \ldots$..., también «...l'hem vist casi terminat més tard...» (Pin i Soler 2002: 147). Esta noticia, además, nos aproxima a la cronología del viaje rumano de Josep Pin i Soler y, si la anterior sugerencia fuera acertada, al tiempo de la estancia turca.

\section{JOSEP PIN I SOLER EN BUCAREST: EL VIAJERO COSMOPOLITA Y LA CIUDAD MIXTA}

\section{Guía de una moderna ciudad}

Tras un sintetizado recorrido que nos vale por umbral, Josep Pin i Soler se encuentra, ya allí, ante una urbe con voluntad cosmopolita, de una modernidad que en su viaje irrumpe y «...causa grata sorpresa atravessant part de l'antiga Dàcia dels romans» (Pin i Soler 2002: 135). El conjunto de sus textos bucarestinos 
se inicia con esa llamada al tiempo que perfila una primera descripción, mediante una retórica acumulativa y de planos cruzados, llena de indicios que remiten a criterios positivistas llevados a la renovación urbanística, y a resultas de la cual entramos en una ciudad moderna, fruto del esfuerzo y de la planificación de unos habitantes igualmente modernos que la han levantado entre accidentes verdaderamente inhóspitos:

Amb constància i ordre, la gent moderna, d'unes terres de sembradura, d'uns estanys mefítics, d'unes maresmes estèrils, n'ha fet eixir jardins hermosos, carrers amplíssims, parcs, teatres, acadèmies, museus, cases d'habitació sumptuoses, hospitals, estacions de ferrocarrils, iglésies, palaus, temples per tots els cultes, seminaris... hotels grandiosos per allotjament de viatgers... (Pin i Soler 2002: 136).

Conectando con ese período y con la referencia hostelera abierta entre los sugerentes puntos suspensivos, el recién llegado a Bucarest abunda en su hospedaje. Su Hotel Continental es signo evidente y abanderado de aquel destacado cosmopolitismo, tanto por los detalles que contiene y por los profesionales que lo atienden como por la comparación con otros hoteles internacionales que - de Niza a Constantinopla, del Cairo a Lisboa, de La Haya a Venecia o de Atenas a Sevilla - tanto forman un mapa propicio para el viajero exquisito como nos informan de la cultura viajera de Josep Pin i Soler mediante una especie de aspa geográfica que, movida por los vientos del viaje como signo de clase, abarca los horizontes de un meta-continente para uso de una minoría exquisita.

Informante, por tanto, de un destinatario privilegiado y con el único con el que parece querer compartir sus modos y hasta su idea de viaje pues «En qüestió d'allotjament: o sol o ben acompanyat, o corte o cortijo» (Pin i Soler 2002: 136), el visitante catalán cumple para con él con una función que el novecientos y su impulso socializador llevará a todo tipo de guías para consumo de un espectro turístico mucho más plural. Anticipándose a estas últimas, de modo escueto pero no menos sugerente, traza en primer lugar, un callejero que atiende a las vías contenedoras de los mencionados signos de modernidad o a las que fueron arterias de la ciudad antigua, proponiéndole un doble destino al hipotético viajero, el de seguir manteniéndose en su medio natural, con sus necesidades y caprichos atendidos allá donde vaya y el de ofrecerle unos rincones históricos, dignos de ser visitados y justificadores del móvil cultural del viaje.

Acorde con ese doble cometido, Josep Pin i Soler ordena también su guía de lugares y de monumentos. Mención a parte del río Dimbonitza que discurre como eje de «...la bonica capital de Romania» y que sólo tiene el problema de la proximidad del Danubio para quedar reducido a la categoría de «riuet» (Pin i Soler 2002: 145), el escritor vuelve a ordenar destinos dignos de ser visitados en función de aquella doble categoría, la social y la monumental. Así se mencionan, por una parte, los «clubs» que, para las actividades masculinas, son «...una cosa indispensable al llur viure» y el «teatre nacional»o «rendez-vous de la millor societat del país» (Pin i Soler 2002: 145, 146); y por otra, mediando la descripción arquitectónica y del programa de dicho coliseo así como de los jardines de cierto estilo belga que animan la zona, se pasa a la rememoración de 
edificios civiles — a propósito de los que aparece la mención a algún que otro «arquitecte francès» o al parecido con determinada «construcció francesa» (Pin i Soler 2002: 146)—, a la de construcciones religiosas — de las iglesias entre las que se reconoce la forma «...bizantina antiga» al palacio arzobispal (Pin i Soler 2002: 146-147)—, y a la de edificaciones privadas — del Ateneo que sorprende por su laboriosa decoración, fruto mixtificador de laboriosos artesanos, a las villas «...tan elegants i correctes com les qui més ho sien», pertenecientes a las familias más ricas y de hábitos cosmopolitas acordes a las sagas más internacionales (Pin i Soler 2002: 147-148). Ese trazado —recorrido que no evita pasar por el Palacio de Justicia, «modern» en el sentido de nuevo como el mencionado Ateneo, y por la espesa vegetación de un parque central que cobija «...llacs i barquetes, kioskes de música, cervecería, restaurant ultradistingit» (Pin i Soler 2002: 148) - sirve de compendio de los trazos que componen el perfil urbano bucarestino: lo francés amalgamado sobre lo bizantino y proyectado hacia lo centroeuropeo; cabe deducir que en Bucarest, por tanto, resalta el modelo más creativo - París, Bruselas -meciéndose en lo exótico - Constantinopla - y mirándose en lo elegante- $-i$ Viena? - . De este modo y sin mencionarlo, se forja en el texto de Josep Pin i Soler el contorno del petit Paris que, en los límites del continente, sedujo a más de un viajero a caballo de los siglos; eje de una geografía que el autor sí notifica en medio de un espacio sugestivamente mágico, el de los Cárpatos coronados por castillos ya convertidos en residencias estivales por aquellos viajeros linajes y presidido por la reina-poeta Carmen Sylvia (Pin i Soler 2002: 148).

Mediante una referencia a las cabeceras de diarios y revistas del lugar y el rescate de dos programas de espectáculos, Josep Pin i Soler nos propone, además, la posibilidad de comprender el rumano al tiempo que hace alguna acotación lingüística de orden morfológico y léxico, apreciando su correspondencia con lenguas románicas más cercanas al escritor. Aún advirtiendo también de las diferencias que dificultan esa intercomprensión pero insistiendo en la inteligibilidad por nuestra parte - con toda seguridad, con un comentario desafortunado sobre el texto de periódico que ofrece como muestra del rumano: «És tan clar que sembla castellà mal escrit» (Pin i Soler 2002: 149) — pero no engañando acerca de la compleja lectura de los textos literarios, aún con la ayuda de diccionarios, el autor concluye a propósito de esa cercanía lingüística y por dos veces:

Patates fregides me fou molta gràcia: cartofe prejicte, que pronunciat sembla carxofes fregides... de manera que la qüestió essencialíssima de menjar és quiestió resolta. Tot català pot viatjar per Romania, segur de que serà tan ben nodrit com sa fam li demani i sa bossa li permeti. (...) ho repetim, pels catalans és facilíssim entendre tot lo que convingui fins fer-se entendre sense saber lo romà. (Pin i Soler 2002: 149-150).

Si se nos ofrecía un callejero esencial y una lista de monumentos y de lugares merecedores de ser visitados, este último nivel informativo y tras esas consideraciones animando a la facilidad de idioma del país visitado, casi hacía esperar un listado de voces y expresiones básicas para moverse comprensiblemente 
entre sus nativos. De hecho, la realización de ese tipo de vocabulario tienta al autor, como prueban las fórmulas griegas de saludo, de llamada a un sirviente y otra variada serie de voces ordenadas en uno de sus textos con motivo de la visita a Grecia, formando una esencial «lingua franca» para uso de viajeros (Pin i Soler 2002: 69). Josep Pin i Soler no llega a ese extremo en el caso del rumano y en nuestro peregrino empeño de convertirlo en precedente de las actuales guías de viaje. Habrá que notificar que, en otro texto, el escritor viajero se mostraba irónicamente despectivo con «...los consells del detestable Baedeker» y con los «baedekistes», tal y como advertíamos en el punto anterior (Pin i Soler 2002: 9, 10). Por tanto y como poco, sí conoce unos patrones con los que no comulga plenamente. Pero sí facilita, acorde con la función de todo texto guía, una imagen asumible de ese nuevo Bucarest a la vez que, con sus consideraciones lingüísticas, aproxima un paraje lejano por donde, en todo caso, siempre podrá moverse uno en francés. Al menos en los lugares de acogida que parece elegir el autor y, seguramente, entre los otros viajeros con que vendrá a coincidir en una correspondencia de elite europea.

\section{Ciudad de contrastes}

Pero conociendo la totalidad de las páginas de Josep Pin i Soler dedicadas a Bucarest, hay que preguntarse si eso es todo lo que cabe en esa perfecta cuadratura; o, en todo caso, si no hay nada más que ofrecer a su lector, algo que vaya más allá de o complete ese medio idóneo para la ocupación buscada por el viajero cosmopolita, ofreciéndole el lujo de un paisaje externo e interno que arrastra consigo pero engarzado en los resplandores de una exótica cercanía. Fuera como fuese, acto seguido de anunciar aquella ciudad nueva de trinca y antes de aquel paseo por los signos de su modernidad, se nos ha advertido de cómo fue de «primitiva» antes del régimen que la ha modernizado y se han dado pistas de su azarosa historia entre el setecientos y el ochocientos, pasando de manos turcas a manos rusas que posteriormente la cedieron para la formación del Principado de Balaquia, siendo «...una vila si bé grandíssima» pero que «...devia semblar una mena de rancho de pastors i pagesos», añadiendo: «...lo qui encara es veu en los suburbis» (Pin i Soler 2002: 135). Con ese periodo, insertado a modo de simple flash en aquel dinámico inicio que se dispone a conducirnos por entre la modernidad bucarestina, se abre como una fisura a favor de una contraimagen de la capital rumana que no va a quedarse en una pasajera llamada en balde, barrida por aquella convulsiva espiral de los tiempos modernos. Veremos agrandarse aquella fugaz advertencia de una naturaleza distinta con motivo de dos referentes que revisaremos inmediatamente. Quizás cumplen con la función de añadir a los intereses del lector e hipotético futuro visitante un componente más de atracción - Bucarest, ciudad de frontera, en los límites del mundo románico con el eslavo, geografía multirracial, continente de tradiciones ancestrales crecido a la luz de la convivencia pluricultural...-; pero, a la postre, se trata de dos componentes que, anclados en su historia anterior, conectan la capital con su país y esto con un mayor grado de realismo superior a cualquiera de los efímeros signos de los tiempos que, hoy sabemos, parece que se levantaron en Bucarest sólo para ser arrasados. Esta segunda opción semeja que es factible a 
pesar del contrapunto que se crea entre esos elementos tradicionales del país y la novedad con que se exhibe la ciudad ante occidente. Siguiendo las líneas de Josep Pin i Soler, no nos atreveremos a decir que, mediante la presencia de esos dos asuntos pendientes de revisión por nuestra parte, se cuestione la idea de modernidad ensalzada con motivo de la visita a Bucarest; pero sí que, en todo caso, aquella noción queda compensada mediante una información de lo ancestralmente rumano, combinatoria que acaba por darnos una imagen más cabal de la lejana realidad que se llega a conocer.

\section{3. 'Lipovani' o 'muscali'}

El primero de esos dos anunciados componentes esperaba a Josep Pin i Soler a las puertas de su flamante Hotel Continental. Se trata, simple y llanamente, de los coches de alquiler o, mejor dicho, de sus cocheros. El caso es que el interés pasa pronto del aspecto de los vehículos a la idiosincrasia de sus conductores: ajenos, al parecer, a la comprensión del idioma del país o a otro medio de comunicación lingüística, dispuestos a hacer un tour completo de la ciudad, circulando o deteniéndose allí donde el cliente se lo indique con la empuñadura del paraguas, también a que su paga se la resuelva el encargado del hotel; y, esto es lo crucial y en lo que abunda el texto de Josep Pin i Soler, pertenecientes a una minoría de origen ruso — «...la secta dels lipovani ${ }^{2}$, una gente verament extraordinària.» (Pin i Soler 2002: 137) — y refugiados en las ciudades rumanas a causa de la persecución del gobierno del país de origen. Pronto se advierte que «Han fet vot de castedat, i per no infringir-lo, cortan por lo sano.» (Pin i Soler 2002: 137). A partir de aquí y de haber notificado que alguna noticia se tenía pero que, finalmente, se estaba en su presencia y se podía dar fe del asunto en cuestión —así se repite un lugar común en la retórica de la literatura de viajes y mediante el que queda dignificado el viajero-escritor ante los ojos de su receptor: «Davant teníem la prova viva de l'existència real d'aquells malaurats que en llur desig de perfecció arriben a l'anorreament.» (Pin i Soler 2002: 137)—, el texto se sumerge en el nivel más profundo de esos inesperados protagonistas de la estancia en Bucarest, experiencia que sólo parecía dispuesta a discurrir por su superficie, la de las muestras de modernidad y de su historia externa. Precisamente a través de la mención a las ansias de sublimación y al «anorreament» comprensible en términos de autodestrucción de aquellos rusos expulsados de su tierra, nos parece que Josep Pin i Soler encuentra ocasión para versar sobre una variante del alma eslava, motivo que tantas páginas literarias europeas ocupó desde finales del ochocientos hasta los años veinte y treinta de la centuria inmediata, yendo más allá de la mera moda y rayando la estética. El escritor catalán da así con un elemento añadido con el que atraer la atención sobre Bucarest y, claro está, sobre su texto.

${ }^{2}$ Donde J. Pin i Soler habla de lipovani, se refiere a muscali, comunidad afincada fundamentalmente en Bucarest, poseedora de los rasgos y hábitos que el autor atribuye a los primeros. Una y otra minoría tenía origen ruso, coincidencia que quizás está en el origen de su confusión. 
Partícipe de ese interés y vehiculador de noticias a su favor, Josep Pin i Soler ahonda en los vericuetos más espiritualistas de la psicología de los lipovani (correcto muscali), desde el extremo purista de su doctrina a lo austero de su aspecto e indumentaria y a lo sigiloso de su presencia. El autor de las páginas aquí revisadas no puede dejar de alabar y agradecer su servidumbre y por razones semejantes entiende que el gobierno sea condescendiente con ellos y la práctica de sus costumbres. Pero no evita afirmaciones que denotan sus recelos ante su fanatismo, ante «...l'aberració de llur concepte vital», ante «...una secta que si socialment és pacífica, humanament és criminal...» (Pin i Soler 2002: 138, 139). En esa dirección y por lo antes dicho acerca de la corriente eslavista, cabe reproducir el siguiente texto donde Josep Pin i Soler no sólo se posiciona ante los extremismos de aquel grupo sino que cuestiona abiertamente a uno de los nombres sagrados de ese sentimiento:

Hi ha qui atribueix llur estranya concepció dels destins humans a prèdiques tolstoianes... però què sé jo! Si bé Tolstoi, admirable artista en lletres, com a filòsof i sociòleg sempre ens ha fet l'efecte d'un trastocat i fins una mica poseur, amb lo de cosir-se ell mateix les sabates i fer-se retratar tot llaurant com un pagès pobre, no volem creure que hagi arribat fins a propagar entre los humils una doctrina contra natura. (Pin i Soler 2002: 138).

Una consideración tocada de ambivalencia tanto en lo referente a Tolstoi — véase en idéntica dirección la entrada a él dedicada en los citados Comentaris o catálogo de la propia biblioteca-como a los lipovani (correcto muscali), volviendo en este segundo caso a insistir en la bondad de aquellas gentes - ahora mediante una última anécdota en torno a un desplazamiento hasta las orillas del Danubio para surcarlas en una de las excursiones allí propuestas, hechos que le hacen envidiar divertidamente al viajero que no se trasladen a trabajar a su tierra, donde todos saldrían ganando, catalanes y rusos-, a pesar de lo cual el autor no puede evitar sus interrogantes a propósito de aquel colectivo. Con el siguiente párrafo y simultáneamente, Josep Pin i Soler parece insistir tanto en sus recelos ante el primitivismo de aquella doctrina como en los márgenes de interés que aquel atavismo eslavo sito en tierras rumanas puede suscitar a los ojos del europeo occidental:

...causa més llàstima que indignació, car després de tot aneu a saber, los desditxats, per quin cúmul de sofriments atávics han d'haver passat per a decidirse a professar llur estranya doctrina, per a arribar al convenciment de que és obra pia el matar ells mateixos les futures generacions!... I tot amb calma, treballant tant com poden, resant sempre, esperant amb beatitud lo desitjat dia del no ser, ni ells, ni ningú més! (Pin i Soler 2002: 139).

\section{4. 'Lautars', 'tarani' y 'modern style'}

El segundo de esos componentes advertidos lo constituyen el «soroll-teixit de Bucarest» y sus «fabricants» (Pin i Soler 2002: 141), doblemente, porque tanto cuenta la atmósfera creada en la ciudad como la catadura de sus ejecutores. 
Como obradores de la melodía de fondo de Bucarest, Josep Pin i Soler destaca la música de los «lautars», ejecutores de tonadas

...sorprenents per la novetat del ritme, per la bravura de l'execució. Recull vivent de tota mena de cants populars, de melopees antigues, d'aires camperols i bèl-lics, de tots los vals vienesos més graciosos, de totes les czardes i poloneses més engrescadores. Ells són l'acompanyament obligat de festins, casaments, bateigs, balls de nuviatge.

Llur cobla es composa senzillament d'una flauta de Pan, d'una viola, d'un violí obligat i d'una cobza, una mena de pandero amb CORDES de guitarra que graten amb dolçor o percuteixen amb fúria. S'abandonen amb tal entusiasme, emportats pel ritme, s'exalten fins a tal punt, que 1 públic calla, i commogut a l'adonar-se de que ja han parat, aplaudeix furiós fins que tornen a començar. No hi ha jardí públic, cervecería, parc, restaurant una mica concorregut on facin falta. (Pin i Soler 2002: 141-142).

Cuadro musical que impone una sonoridad balcánica, cualquier comparación explicativa ensayada por Josep Pin i Soler con los cantores ciegos de su tierra conduce, inexorablemente, a más diferencias que a alguna coincidencia. A aquel colectivo se añade el de los «musicanti», retratados como artistas callejeros provenientes de los Cárpatos y sobre los que se agolpan adjetivos como «ètnics»o «estranys» (Pin i Soler 2002: 142); a alguna de las danzas de estos últimos sí se avienen bailes del Camp de Tarragona que al viajero le recuerdan, unos y otros, «...aquells balladors de teies de certs pobles de la costa de Llevant, reminiscència dels portadors d'antorxes grecs i lo que representaven ens sembla algun misteri... gestes d'hèroes, coses de sants.» (Pin i Soler 2002: 142). Total y todo unido, la visión de lo atávico, de lo ancestral, de lo folklórico que concede identidad a una tierra y a sus moradores. En suma, la tradición, la marca de diferencia que señala la realidad del paraje visitado y que, para el viajero, tiene el acicate de lo exótico.

El tejido de Bucarest, por su parte y avanzando en el texto de Josep Pin i Soler, no lo componen sólo esos músicos y danzantes con origen en lo profundo del país y alguna que otra minoría como las de los refugiados rusos citados con anterioridad; cuentan también judíos de los más variados orígenes geográficos, campesinos trayendo variados productos mediante primitivas carretas, mercaderes búlgaros con ropajes típicos y canastillas cargadas a sus hombros, valacos con primitivas indumentarias, población rural y marinera que guardan en sus vestimentas piezas que ora parecen bereberes, ibicencas o valencianas, ora rusas por sus dibujos... Dos cuestiones a propósito de ese cúmulo de información que, digamos sólo de pasada, se enriquece con la descripción entre etnográfica e impresionista del autor: por una parte, esa atracción demográfica hacia Bucarest tiene que sustentarse en la vitalidad y la riqueza de la capital en el tiempo en que el texto aquí comentado nos permite visitarla, pujanza sobre la que se levanta la urbe nueva que primero se nos ha dado a conocer, movimiento de expansión que, a su vez y circularmente, forja su atractivo ante la población extramuros; y por otra parte, el choque principalmente visual impuesto por esta última presencia ante aquel paisaje de ciudad moderna que debe haber suscitado otro tipo de viandante rumano. 
Acerca de esa variada composición urbana y tras destacar la variedad y el colorido de aquellas ropas tradicionales, leemos en el texto:

Inútil dir que la menestralia de la ciutat no es permet semblants dibuixos. Lo monstre Mediòcritas los té sota el seu jou, i com si fossin gent de qualsevulga part veureu als menestralets de Bucarest, vestits a la moda dels nombrosos menestrals germànics que habiten llur vila; portant com ells corbates de colors llampants amb agulles piteres de similor, armilles mirífiques, bastó amb puny complicat, fins porten lentes amb cordonet per poc que llur vista ho permeti, $\mathrm{i}$ tenint com models els tedescs, visitant com ells jardins públics i cerveseries, establiments on regna Gambrinus, i allí s'atipen de llesques de pernil fumat, de rodonetes de llonganisses vermelles, de rovells d'ou dusos, que engorgiten a copia de cervesa; cantant, ballant pesadament, llordament, suats, regalimant beguda, abandonant les danses i diversions indígenes... que prou se veu ja només tenen adeptes entre els camperols, entre la gent de servei i mariners del riu (...). (Pin i Soler 2002: 144).

Josep Pin i Soler, por tanto, no sólo nos responde con la descripción del aspecto externo de los bucarestinos, marcando la dicotomía previsible entre los individuos con indumentaria ancestral y los que visten modernamente al estilo germánico, sino que la amplía al cambio de hábitos entre uno y otro grupo social, campesinos y ciudadanos. Texto adelante, aún más explícitamente, el autor sitúa a aquellos residuales rumanos ante el imparable progreso nivelador, celebrando sus encuentros populares en los prados que rodean Bucarest, marcando unos círculos de transición entre el país que habitan y la ciudad en la que sólo son episódicos transeúntes, el Bucarest que se ha inclinado hacia un modelo sustitutorio. Hasta aquí y de acuerdo con lo planteado - el autor, al constatar ese doble componente, ofrece a su receptor un aliciente más o nivela más realistamente el escenario informado-, todo parece seguir su curso previsto. Pero hay que preguntarse si es lógica la recriminación a la clase media bucarestina de su giro hacia los modelos alemanes, de ropa y de costumbres, para dotar a la ciudad moderna de nueva creación de unos patrones igualmente nuevos; si es coherente después de haber cantado el Bucarest cosmopolita o si realmente se esperaba que, entre las amplias avenidas y las confortables villas, siguieran transitando rumanos ataviados con trajes tradicionales camino de los ministerios o de suntuosos establecimientos. Josep Pin i Soler, viajero realista, no deja de detectar el componente estrictamente rumano en su visita a Bucarest; a la vez viajero de elite, cae en la contradicción de celebrar la existencia de una infraestructura y de un modelo urbanos que él necesita allá donde vaya al tiempo que parece exigir a la población nativa vivir de espaldas al progreso de las modas y de las costumbres; o tal vez, viajero con ciertas filias y fobias, la opción por el modelo alemán no le parezca la más oportuna, coincidiendo una vez más con su juicio personal contrario a los alemanes a los que, en otro texto y en calidad de viajeros, ve como «regateros tedeschi»y «malgirbades tedesques» (Pin i Soler 2002: 10).

En cualquier caso, todo parece resolverse una vez que se entra en los círculos de «la gent distingida»: Josep Pin i Soler no ve ninguna diferencia en Rumanía con respecto a la clase aristocrática de otros países instalada en sus res- 
pectivas capitales, ni en sus hábitos, ni en sus residencias, ni en su manera de sentir «...lo elegant, lo confortable, sense necessitat de copiar-ho de cap estampa.»; esto último parece contradecir la manera en que, según se afirmó en otro momento, se ha levantado el nuevo Bucarest; y en todo caso, si guarda una diferencia para las damas de la aristocracia con base rural, ello le permite abandonarse a las consideraciones del tipo de «espirituals» 0 «enciseres» (Pin i Soler 2002: 150), puntos en que el autor parece rayar los límites de la ironía para con ciertos tópicos, sea lo sublime del gusto aristocrático, sea la extremada sensibilidad femenina de tan lejanas tierras. Finalmente y sin dejar de referirse a las reivindicaciones territoriales que aspiraban a restaurar la Dacia romana, Josep Pin i Soler sentencia que si Rumanía «...és una nació altament interessant», su capital «...és una ciutat tan gran o més que la nostra València, però molt més modern style.» (Pin i Soler 2002: 150). Todo lo escrito por él nos hace pensar que, no obstante el margen de diferencia indicado, tuvo que haber tantos tarani rumanos como llauradors valencianos boquiabiertos delante de las fachadas modernistas de sus respectivas capitales. Unos y otros iban y venían por las calles de sus ciudades mientras, una y otra, intentaban entrar en la nómina de la modernidad. Seguramente, eso sí, una con más empeño que otra. Y una, mucho antes que la otra. Pero con una coincidente humanidad ciudadana y campesina doble que evidenciaba la naturaleza mixta de las comunidades que regían a finales del ochocientos.

\section{JOSEP PIN I SOLER EN CONSTANTINOPLA: LA CÚPULA INSCRITA EN EL CUADRADO}

\section{Escrituras y experiencias en el Cuerno de Oro}

Las páginas dedicadas a «Constantinoble» o, en menos casos, «Istambul» - con mucho, el destino a propósito del cual Pin i Soler escribió más copiosamente- - se ordenan como un todo cerrado, dibujado de manera circular entre el «A l'arribar a Constantinoble...» y el «...eixia de Constantinoble» del inicio y del final absolutos del texto recopilatorio (Pin i Soler 2002: 81, 131). Unidad significativa acerca de la cual el autor se permite, primero, el guiño de proponerse «... una entrada preparada» (Pin i Soler 2002: 81), repetida, dado que la lluvia copiosa del día de llegada no ha permitido reconocer el afamado perfil de minaretes y cúpulas que no fueran, estas últimas, las de los necesarios paraguas; $\mathrm{y}$, segundo, sugerir un regreso a Constantinopla por la vía norte, núcleo textual extenso y construido con potenciales verbales que aventuran lo que así se iría viendo y descubriendo (Pin i Soler 2002: 118-122), páginas que, pensamos, remiten a otro viaje con idéntico destino. Contamos a favor de esta hipótesis con que, por Bucarest, pasó, como poco, en dos ocasiones distantes en el tiempo. En cualquier caso, ahora lo que nos interesa destacar es que una u otra posibilidad - la de uno o dos viajes hasta la orilla finalmente turca - queda recogida como una única experiencia viajera, convirtiéndose el relato de los hipotéticos viajes a Constantinopla en un meta-viaje cuyo interés, más allá de la relación de pasos y hechos, se va a desprender de la comprensión que, con alcance universal, se proyecta de aquel espacio y de sus habitantes e historia. 
No diremos que, a lo largo de todas esas páginas y cumpliendo con los requisitos de la literatura de viajes, no se transite por los núcleos urbanos que constituyen la ciudad visitada ni que no se pase por mezquitas, palacios, baños turcos y placenteros balnearios; tampoco que, aquí y allá, no emerjan indicios de aquel viajero señalado como cosmopolita, de un tiempo en que el cosmopolitismo conllevaba ciertas servidumbres como pudieran ser dar las noticias oportunas sobre la vida de hotel, recordar la nómina de viajeros literariamente ilustres, notificar la presencia de una amistad notoria en el lugar de destino, a ser posible la de un diplomático o rico empresario, resaltar la acogida temporal en una lujosa villa $\mathrm{o}$, por qué no, un paseo a caballo circundando las murallas... Cada uno de esos tópicos tiene su lugar preciso en el recorrido espacio-temporal ordenado por Pin i Soler. Los unos conllevan textos que crecen mediante la descripción oportuna, la nota histórica ajustada y la apreciación personal, todo ello, como es de prever, con Santa Sofia y su cúpula a la cabeza, recorrido ejecutado en uno de sus fragmentos al ritmo de la paralelística cláusula verbal «...vèiem ...vèiem ... revèiem ...revèiem ...revèiem...» (Pin i Soler 2002: 92-93) que le concede, tanto al lugar visitado como a la mirada allí desplegada, una sacra textura por su eco monódico; los otros se facturan con una agilidad de trazos contagiosa, transmisora de una creciente modernidad que pudiera hacer las delicias de los urbanitas lectores que soñaban desde sus butacas de lectura con experiencias viajeras parejas, así las prosas dedicadas a la estación termal de Teràpia, entre yates, bañistas y damiselas que ora se saludan en francés, ora bromean en inglés por entre los ajardinados paseos (Pin i Soler 2002: 111-114). Ese doble nivel compositivo, el de las visitas documentadas y el de los hábitos de clase, holgadamente cumplido uno y otro por Josep Pin i Soler, facilita la captatio del uno compartido entre emisor \& receptor de la crónica de origen, actantes que se corresponden con un mismo sistema cultural. Pero, no obstante esos lugares comunes -razonables en una literatura de viajes que, además y por primer destino, iba a contar con la columna de la publicación periódica y, por tanto, con una lectura y consumo de ejecución rápida y de efecto impresionista-, en su entramado textual tiene cabida otro tipo de ejercicio por parte del autor. Siendo nosotros de la opinión de que en este último se halla el nexo que cohesiona la totalidad del texto dedicado a Constantinopla, dotándolo de un discurso interno, ese nivel profundo supone la assumptione de un sistema cultural ajeno, tránsito mediante el que aquel uno compartido aprende del otro a favor de uno mismo.

\section{Cúpulas y minaretes}

La Constantinopla buscada por Josep Pin i Soler — atacada desde las primeras líneas con espíritu de flanêur y con manifiesta voluntad de instruirse en la realidad visitada, insertándose en el medio y buscando informantes que estén por encima de «...guies, històries i geografies» al uso (Pin i Soler 2002: 81-82) — debe haberse enciclopédicamente previsto como una aculturación helénica, romana, bizantina, musulmana, no ajena al paso de pueblos románicos - así el catalán, presencia e inserción histórica con lo propio a las cuales alude repetidas veces el autor - y al fin otomana. Pero el viajero, contra esa previsión, parece encontrarse con una realidad autónoma. Advirtiéndose a si mismo que «...no hi 
havia tal ciutat de Constantí!», aseveración que parece englobar todo aquel macrocosmos previamente construido, tendrá que reconocer que «...Constantinoble no existia»; sólo así y frente a aquella mixtificación culta, podrá posicionarse ante y adentrarse por entre la conjunción de «... aigua, terra, arbres, llum, murmuris, colors i cel, tot allò era Constantinoble» (Pin i Soler 2002: 83).

Ante ese espacio mental y sensorialmente reconducido que sí es Constantinopla, Josep Pin i Soler afronta su etnia plural y su multiculturalidad, no oculta sus desajustes desde su sensibilidad helénico-latina, asume la parte de culpa occidental en la destrucción de un pasado glorioso tanto como que la cultura cristiana no fuera ajena a la abolición de unos valores que allí, en esa Constantinopla hecha por sobre su propia historia, se intuyen enriquecedores... (Pin i Soler 2002: 84-88). De este modo, con una predisposición que se nos intuye como permeable, el viajero practica el mencionado salto de inmersión en aquel magma, a la postre y como poco bimembre, sobre el que se destacan «...aquelles cúpules cristianes i aquells minarets mahometans que es dibuixen damunt lo blau del cel i que de tan lluny se veuen» (Pin i Soler 2002: 89). El escritor asume unas coordenadas emanadas de lo plural, generadoras de una geometría propia que se ansía absoluta; contenedora esta última de un universo surgido de la conjunción entre fuerzas extrañas, latinas y orientales, Josep Pin i Soler, visitando Santa Sofia y tratando sobre el arte bizantino, se afirma en la búsqueda de permanencia de aquel medio. Se trata de un afán que le llevara a la inscripción del círculo en el cuadrado, forma rodeada en sus segmentos por cuatro pechinas, allí donde, en el paso de templo cristiano a mahometano, se elevarán cuatro minaretes, delimitación que, en suma, plasma una adopción representativa definitiva: «...la cúpula inscrita en lo quadrat» (Pin i Soler 2002: 91).

Insertado él mismo en esa forma perfecta, Josep Pin i Soler equipara la presencia de dioses diversos en un Dios único y universal y conjuga las oraciones de los más diferentes fieles en una alabanza y un ruego unívocos; allí adentro, la asunción de la historia de la humanidad se le totaliza de una manera radical:

Aquell temple diu amb eloqüència summa que la humanitat és una, que els pobles quals diferències semblen enormes neixen tots, creixen, predominen i s'apaguen, per a ser llevat de noves generacions que tornen a créixer, a predominar o a ser sotmeses... girant eternament dintre el cercle de sa comprensió limitadísima, cercant afanyosos la realitat dels sers, treballant fins a morir en l'eterna tasca de resoldre lo perquè del viure... i desesperant de trobar mai satisfacció al punyent desig de conèixer l'august misteri, arraulint-se, qual coloma poruga, sota les voltes del temple...» (Pin i Soler 2002: 94-95).

Desde ese ángulo de mira y con tal predisposición por su parte, Josep Pin i Soler aboga por una enriquecedora y global unicidad de la experiencia humana; se muestra contrario al culto a los círculos de limitadísima comprensión, a las diferencias excluyentes que nos abandonan, deshumanizada y aisladamente, ante los interrogantes de todo ser creado, convirtiéndonos en miedosas palomas revoloteantes bajo la bóveda del universo. Ese es el primordial prisma a través del cual, en las páginas sobre el destino aquí visitado de su mano, se alcanzan los 
más variados asuntos; tal y como queda dicho, desde la visita monumental a los hábitos de aquella viajera minoría selecta que, turísticamente, empezaba a viajar por el mapa europeo y hasta el confín turco o por las orillas y los desiertos africanos. Elegida aquella mirilla, de lo uno y de lo otro, casi siempre, recibimos una lectura o extraemos una enseñanza que se desprenden de la forma conjugable de atender a la historia desde una doble frontera o de encarar según qué reacciones desde según qué sensibilidad. No es ajena a tal planteamiento la posición de Josep Pin i Soler ante los individuos y las culturas diferentes al sistema propio y con los que se interrelaciona en la geografía de llegada. Atendamos a esos encuentros para acercarnos a la demostración de aquella idea, ejecutada por parte del autor ante unos otros concretos.

\section{Judíos}

Una primera presencia que se alcanza como distinta pero no ajena al propio sistema cultural de origen es la de los judíos, más concretamente la de los judeoespañoles un día expulsados de Hispania y ahora encontrados en la urbe visitada (Pin i Soler 2002: 97-109). La característica fisiología de la raza hebrea, adobada con nombres, linajes y rasgos lingüísticos de corte hispánico, nos sitúa ante una hermandad de fondo que reduce cualquier distancia imaginada. Ante ese interlocutor, el autor reconoce tanto una bondad y dulzura de formas y sentimientos, incluso cuando se está recordando la expulsión de la patria común, como la propia marginación entre judíos cuando se nos adentra en Balata (Pin i Soler 2002: 102, 106-107). Lo positivo y lo negativo caben en un retrato que, a partir de los más personalizados intercambios y del anecdotario relatado, se pretende certero.

Focalizados los judíos como una colectividad que discurre ante nosotros contra aquel paisaje, se plantea el contraste (Pin i Soler 2002: 108-109). Se ordena esa contraposición entre «ells, los judeos» y «un de nosaltres», remitiendo, según el rasgo contrastado, a «un franc» o denominación válida para todos los latinos y a un parejo «grecollatí». Ante esos sujetos aprendemos que, frente a la implicación del uno propio del escritor y de su lector en la ciudad y los detalles que acontecen a su alrededor, ese otro judaico pasa ajeno, ausente y sumido en sus preocupaciones, proyectando una presencia eternamente nostálgica, extraño a todo lo externo y encerrado en su mundo familiar; se destacará, además, su serenidad en situaciones en que uno de los nuestros no dejaría de mostrarse sino como «un energumen». De este modo, contención y beatitud hebraicas se oponen a la extroversión y al impulso violento que parecen connaturales a los latinos. La contraposición propicia el aprendizaje desde el lado más propenso a excesos, pero nada se plantea ni enfrenta de manera extrema. Cada pueblo y tradición tienen su perfil y, mirándose unos a otros de acuerdo con la práctica de Pin i Soler a su paso por Constantinopla, cabe un deseable perfeccionamiento por parte del ser humano. Hasta aquí, aquel discurso de fondo que, decíamos, cohesiona la escritura del autor sobre este viaje y nos nuestra su universalista talante humanista, se ve ratificado mediante su atención a la psicología y al proceder judíos. No obstante esta prueba de coherencia con el propio pensamiento 
por parte de una experiencia y de un contacto dados, de la sentencia con que se cierra el texto dedicado al pueblo judío se colige tanto que aquel esperanzador ideario de Pin i Soler no está desprovisto de limitaciones, acudiendo quizás a la tipología judaica perfilada en el sistema cultural nativo, como un sentimiento que, dramáticamente, iba invadiendo la Europa del cambio de centurias: «En resum, que són agradables per a ser manats. Com a amos cal fugir-ne, cal no deixar-los prendre peu enlloc.» (Pin i Soler 1002: 109).

\section{Musulmanes}

En otro texto (Pin i Soler 2002: 115-122), el autor atiende al presente otomano asentado, eso sí, sobre antiguo «realme hel-lènic» y aún sobre otros pobladores más arcaicos (Pin i Soler 2002: 115), apreciaciones que parecen hechas a favor de una cierta adscripción territorial de lo que se reconoce, recordémoslo, como grecolatino, en el fondo propio o, al menos, no extraño. En cualquier caso, la filiación religiosa musulmana de los turcos permite a Josep Pin i Soler la revisión contrastiva de aquellos creyentes con los fieles de la fe propia, entre «los moros» y los «cristians».

Así se desarrolla una tabla que, atendiendo a comportamiento ético, seguridad urbana, fidelidad y sobriedad, castidad, moralidad y religión, también a su obligada defensa ante el interesado ataque enemigo por parte de los musulmanes (Pin i Soler 2002: 116-117), siempre deja en mejor lugar a estos últimos frente a los cristianos o, por extensión, occidentales. Aún más, los mencionados moros nunca son merecedores de la tópica y contraria fama que, en cada uno de esos asuntos, se les atribuye, para nada si les compara con «...certs jueus o cristians que als ulls dels qui no miren prim passen per models d'hòmens civilisats»; sólo opinará lo contrario quien mantenga de ellos una imagen heredada, aquel que únicamente «...los conegui per operetes amb odalisques i serrallos»; aquel, occidente en suma y desde una supuesta posesión de la verdad, que les sigue queriendo hacer pagar — «Bé els europeus los fem pagar...», «Bé els fem pagar...», «...els diplomàtics fan pagar als néts...»- pasados tiempos de luchas e invasiones, cuando lo que habría que reconocer es la consecución de la capital visitada, aquella en la que el escritor y viajero descubre una enriquecedora encrucijada cultural, «...la Reina indiscutible de tot lo Mediterrani.» (Pin i Soler 2002: 116-118).

Este texto no muestra ningún resquicio en su desarrollo, tal y como, al final, sucediera con la parte dedicada a los judíos. Por la manera en que se ordena la secuenciación sobre los ataques a los musulmanes superados por las acusaciones contra los occidentales, se nos antoja pareja a aquella que, en las letras medievales, rebatía las críticas misóginas mediante la expresionista revelación de los vicios masculinos, desembocando los documentos en cuestión, en una literatura andrógina. Josep Pin i Soler magnifica lo positivo del comportamiento musulmán en las cuestiones tratadas y acentúa lo negativo de los supuestamente civilizados occidentales. No hay, en este caso, la paridad, no por suave menos efectiva, mediante la que se contramiraban judíos y cristianos en el texto mencionado con anterioridad. El autor se afirma, aquí y con mayor radicalidad, en la 
corrección que se debieran aplicar los suyos y la ejemplar oportunidad que le propicia la sociedad visitada. Cabe preguntarse acerca del extremismo de su contraste y del brusco movimiento con que se inclina el fiel de su balanza por causa del peso ético de unos frente a la ligereza de las convicciones de sus opuestos. En cualquier caso, habrá que aceptar que la más positiva valoración del espectro socio-cultural visitado deriva de la cuidadosa mirada y de la sensible atención de su entendimiento ante el espectáculo humano contemplado, esa realidad de la que los suyos debieran aprender y a propósito de la cual Josep Pin i Soler pretende romper con la perpetuación de una tópica interesadamente mantenida desde occidente. Aquello que, cierto es, se le escapó, casi instintivamente, a propósito de los judíos.

\section{El hombre colectivo}

La recopilación de los textos de Josep Pin i Soler sobre su provechosa estancia en tierras ya turcas, lamentablemente no acompañada de la datación de cada entrega, se cierra con un título, Istanbul. Cap de dol (Pin i Soler 2002: 123-131), que, a ciencia cierta, debe figurar entre los momentos más acertados de su obra, por la gradación de sus contenidos, por la catadura ensayística de su discurso y por la seguridad y alcance de su lenguaje. Para seguir en este registro laudatorio, nos faltaría saber la mencionada carencia de la datación y confirmar que esa fue su última entrega de periodismo viajero desde Constantinopla. En todo caso, ese es el texto que se cierra con la ya mencionada salida de la ciudad.

Lo cierto y lo que nos parece más significativo es que, para esas páginas puestas al final, Pin i Soler reserve el tema de la muerte - el encuentro con un séquito mortuorio cuando, tras un rico almuerzo en una popular taberna, contaba con dar un paseo ecuestre-, la de un joven cuyo duelo acaba por encabezar (Pin i Soler 2002: 123-126). La escena es construida con todo lujo de detalles, aquellos que nos introducen en los rituales de los musulmanes y aseguran una determinada y efectista atmósfera. Pero es cuando queda asegurada esa relación con su contagiosa y no menos dolorosa hermosura, el momento en que Josep Pin i Soler da un giro a su escritura. Súbitamente nos sitúa en la aseveración de aquello que trasciende de lo visto, para reinstalarnos en aquella comprensión que venimos destacando desde el inicio de nuestras páginas:

I sense esforç, pasejant per aquelles terres no catòliques, no apostòliques, no romanes, d'Orient, veia que tot home de criteri prou ample pot admetre que altres sers humans pensin sobre els greus problemes d'una manera diferenta de la seva, sia eix home docte pastor o modesta ovella se sentirà per força tolerant per la manera de ser moral dels pobles que visita, i que, la moral no essent matèria independent sinó conseqüència de principis, al veure temples, al contemplar manifestacions externes d'oració, de Fe en sers o principis que li són estrangers deduirà de lo que veu, de lo que escolta, conclusions que li diran lo immutable que és lo principi de la vida, lo semblantes que són fins les creències que semblen més oposades. (Pin i Soler 2002: 126-127). 
Este fragmento aparece entre una primera llamada a los ritos mortuorios prehistóricos o egipcios y una más extensa relación de los misterios de Eleusis en la que el escritor trasciende poéticamente la justificada información histórica; también junto a una encomiástica glosa sobre las verdades cristianas acerca de la eternidad, abierta a unos inciertos puntos suspensivos cuando se trata de aquello en que se nos permite confiar por fe (Pin i Soler 2002: 126, 127-129). Pero, proyección del sentimiento atesorado durante el acompañamiento del entierro, Josep Pin i Soler avanza hacia el final de sus páginas insistiendo en lo universal del ser humano y de su experiencia vital, instalándose en una coordenada en la que se cruzan los elementos de todos aquellos ritos y el alcance de cada una de las creencias subyacentes, curiosamente reflejadas en una escena y puesto de mercado, tras su vuelta, de la muerte a la vida, del cementerio a la orilla del Bósforo, ante los vaporcillos sobrecargados de viajeros (Pin i Soler 2002: 129-131). No obstante, no sin haber afirmado con anterioridad que «...l'home col-lectiu ha tingut de tornar a estudiar l'eterna lliçó de les coses, sempre presentides, algun cop ja casi desxifrades i tot seguit tornades a emboirar per la curtetat de la vida humana, pels cataclismes còsmics i socials que com ventada escampen les volves de saber apilotonades per generacions efímeres.»(Pin i Soler 2002: 129). Ahí vuelve a escucharse al intelectual que confía en las sucesivas lecciones de la historia y en el aprendizaje de las diversas experiencias humanas provenientes de las más diferentes culturas. Un pensador moderno y de formación liberal que desea constatar fervientemente una creciente tolerancia entre diversas ideas y religiones. Constantinopla le ha valido como escenario probatorio desde la frontera musulmana. Geografía desde la que, se nos dice, ya no se practica el proselitismo. Quizás y respecto de ese asunto se nos esta advirtiendo que el cristianismo también debiera aprender, controlando sus afanes evangelizadores. $\mathrm{O}$, por extensión, tal vez se está clamando por que la cultura occidental debiera dejar atrás la impositiva prepotencia de sus modelos.

\section{BIBLIOGRAFÍA}

Erasmus, Desiderius (1910) Elogi de la follia, traducción precedida de un comentario sobre la vida y obras de Erasmo por J. Pin y Soler, Barcelona, Henrich \& $\mathrm{C}^{\mathrm{a}}$.

Montoliu, M. de (1947) Pin y Soler, escritor humanista e independiente, Tarragona, Publicaciones del Excmo. Ayuntamiento de Tarragona.

Pin i Soler, Josep (1915) Regles morals i de bona criança, Barcelona, Editorial Ibérica.

Pin i Soler, Josep (1923) Libro de la patria: coloquios sobre cosas y tierras de España, Barcelona, Ed. Cervantes.

Pin i Soler, Josep (2002) Orient. Vària. III, a cura d'E. Velázquez, Tarragona, Arola Editors / Ajuntament de Tarragona.

Pin i Soler, Josep (2004a): Articles i discursos. Proses disperses, a cargo de E. Velázquez, Tarragona, Arola Editors / Ajuntament de Tarragona. 
Pin i Soler, Josep (2004b): Comentaris sobre llibres $i$ autors, texto a cargo de S. Solé, prólogo de J. M. Domingo, Tarragona, Arola Editors / Ajuntament de Tarragona.

Pla, Josep (1969): Les escales de Llevant, Obres completes, Barcelona, Destino, vol. 13.

Pujals, J. M. (1994): La literatura de viatges en Pin i Soler, Actes del Simposi Pin i Soler (Tarragona, 26-28 novembre 1992), a cargo de F. Roig y J. M. Domingo, Tarragona, Diputació de Tarragona / IET Ramon Berenguer IV, pp. 289-298.

Solà M. (1966): Pròleg a De les terres mediterrànies de Josep Pin i Soler, Barcelona, Edicions 62, pp. 5-12. 
